\title{
ANALISIS KONDISI FISIK ATLET WUSHU SANDA PUSLATKOT KEDIRI DALAM MENGHADAPI KEJUARAAN PROVINSI JAWA TIMUR TAHUN 2018
}

\author{
Yulingga Nanda Hanief \\ Program Studi Pendidikan Jasmani, Kesehatan dan Rekreasi, Universitas PGRI Kediri, Kediri, Indonesia \\ *yulingganandahanief@gmail.com
}

(Received: March 2019 / March 2019 / Accepted: March 2019)

\begin{abstract}
ABSTRAK: Tujuan penelitian ini adalah untuk mengetahui kondisi Fisik atlet wushu Puslatkot Kediri dalam menghadapi Kejuaraan Provinsi Jawa Timur Tahun 2018. Jenis penelitian adalah non eksperimen dengan teknik pengumpulan data menggunakan metode survey dan teknik tes. Subyek penelitian ini adalah seluruh atlet wushu Puslatkot Kediri sebanyak 15 atlet yang terdiri dari 7 atlet putra dan 8 atlet putri yang untuk disiapkan pada Kejuaraan Provinsi Jawa Timur Tahun 2018 di Ngawi. Teknik sampling yang digunakan adalah total sampling. Instrumen dalam penelitian ini menggunakan tes dan pengukuran. Berdasarkan hasil analisis diperoleh data kondisi fisik atlet wushu Puslatkot Kediri dengan kategori baik sekali sebanyak 1 atlet, kategori baik sebanyak 2 atlet, kategori cukup sebanyak 7 atlet, kategori kurang sebanyak 4 atlet dan kategori kurang sekali sebanyak 1 atlet. Kesimpulannya kondisi Fisik atlet wushu Puslatkot Kediri dalam menghadapi Kejuaraan Provinsi Jawa Timur Tahun 2018 dalam kategoi cukup.

KATA KUNCI: $\quad$ Analisis, Kondisi Fisik, Wushu.
\end{abstract}

ABSTRACTS: The purpose of this study was to determine the physical condition of Puslatkot Kediri wushu athletes in facing the 2018 East Java Province Championship. This type of research is non-experimental with data collection techniques using survey methods and test techniques. The subjects of this study were 15 Puslatkot Kediri athletes consisting of 7 male athletes and 8 female athletes to be prepared at the 2018 East Java Province Championship in Ngawi. The sampling technique used is total sampling. The instruments in this study used tests and measurements. Based on the results of the analysis obtained data on the physical condition of Puslatkot Kediri wushu athletes with very good categories as many as 1 athlete, good categories as many as 2 athletes, sufficient categories as many as 7 athletes, less categories as many as 4 athletes and very less categories as 1 athlete. In conclusion, the physical condition of Puslatkot Kediri wushu athletes in facing the East Java Province Championship in 2018 is sufficient.

KEYWORD: Analysis, Physical Condition, Wushu.

\section{PENDAHULUAN}

Wushu adalah cabang olahraga beladiri yang berasal dari Negara Cina ( $\mathrm{Ma}$, Sun, Lu, Ma, \& Jiang, 2017; Lin \& Lecheva, 2013; Lu, 2008). Wushu belum begitu popular di kalangan masyarakat Indonesia, namun prestasi wushu Indonesia di tingkat Internasional sangat baik. Berdasarkan rentetan prestasi yang diraih Indonesia pada cabang olahraga wushu, wushu merupakan cabang olahraga yang masih terbuka lebar untuk mencapai prestasi tertinggi. Tidak hanya itu, perkembangan wushu di beberapa daerah di Indonesia juga semakin pesat. Pada pembinaan atlet baik tingkat daerah, provinsi maupun nasional, faktor kondisi fisik benar-benar diperhatikan guna meningkatkan performa atlet sehingga dapat mencapai puncak prestasi. Latihan kondisi fisik memegang peran yang sangat penting dalam program latihan atlet, terutama atlet pertandingan. Hal ini telah terbukti dari hasil penelitian Ambara \& Wijono (2017) yang menunjukkan bahwa ada hubungan yang signifikan antara kondisi fisik dengan prestasi atlet wushu sanda.

Dalam studi sebelumnya terkait wushu sanda, para peneliti telah menerbitkan artikel 
terutama berfokus pada kondisi fisik (Ambara \& Wijono, 2017; Mylsidayu, 2017; Selviah, 2015). Kondisi fisik merupakan aspek yang penting dalam pencapaian prestasi. Kondisi fisik adalah kemampuan mendasar dalam mengembangkan prestasi (Wiwoho, Junaidi, \& Sugiarto, 2014). Kondisi fisik adalah salah satu syarat yang wajib dimiliki oleh atlet dalam usaha peningkatan prestasinya. Physical condition is a necessary requirement in improving an athlete's performance, and may even be regarded as a basic necessity that cannot be postponed or negotiable (Hanief, Puspodari, \& Sugito, 2017). Kondisi fisik adalah salah satu faktor yang penting dalam pengembangan taktik, teknik, maupun strategi dalam setiap cabang olahraga. Menurut Wiwoho et al., (2014) kondisi fisik ada 10 yaitu: 1) Kekuatan, 2) Daya tahan, 3) Daya otot, 4) Kecepatan, 5) Daya lentur, 6) Kelincahan, 7) Koordinasi, 8) Keseimbangan, 9) Ketepatan, 10) Reaksi.

Salah satu yang menarik adalah Wushu Sanda kota Kediri. Wushu Sanda memiliki catatan prestasi yang sangat baik dari tahun ke tahun di semua kejuaraan. Pada tahun 2011 Wushu Sanda meraih 1 emas, 4 perak dan 4 perunggu pada Pekan Olahraga provinsi Jawa Timur III di Kediri. Selang 2 tahun, mereka meraih 3 emas, 2 perak dan 1 perunggu di Pekan Olahraga provinsi Jawa Timur IV di Madiun. Pada tahun 2015, mereka meraih 5 emas, 1 perak dan 1 perunggu, yang mana pencapaian ini melebihi target yang sudah ditetapkan.

Pencapaian prestasi tersebut, tentunya tidak terlepas dari pola pembinaan. Hasil riset Nisa' (2017) yang menyimpulkan bahwa pola pembinaan atlet di sasana Wushu sanda Kota Kediri ini sangat baik karena sasana ini membina atlet mulai dari nol sampai menjadi atlet yang berprestasi dengan program latihan yag terstruktur dengan jelas, dan tersedianya infrastruktur dalam kegiatan latihan.
Upaya untuk mencapai prestasi tentunya banyak faktor diantaranya adalah faktor internal dan faktor eksternal. Faktor pencapaian prestasi yang bersumber dari internal tentunya tak lepas dari kondisi atlet itu sendiri. Sementara faktor eksternal berasal dari luar yang dapat berupa pelatih, manajemen organisasi, sarana dan prasarana dan lain-lain. Faktor internal yang menarik adalah kondisi fisik. Hal ini sesuai apa yang dikatakan oleh Harsono (2015) bahwa kondisi fisik adalah salah satu faktor pencapaian prestasi atlet.

Pada cabang olahraga wushu, terdapat 2 kategori yaitu kategori seni dan bertanding. Keduanya saling membutuhkan kondisi fisik untuk mendongkrak prestasi. Adapun komponen kondisi fisik atlet wushu yang dominan menurut Ambara \& Wijono (2017) adalah daya tahan, daya ledak otot tungkai, keseimbangan, kecepatan, kekuatan otot lengan, kekuatan otot perut, fleksibilitas, kelincahan, koordinasi mata dan tangan. Dari semua kondisi fisik yang disebutkan, penelitian ini hanya membatasi pada aspek kekuatan otot tungkai, daya tahan otot perut, kelincahan, daya ledak otot lengan dan daya tahan (VO2max).

\section{METODE PENELITIAN}

Sesuai dengan tujuan yang ingin dicapai pada penelitian ini, maka bentuk penelitian ini adalah penelitian kualitatif.

Populasi dalam penelitian ini adalah semua atlet Wushu Sanda Kota Kediri yang tergabung dalam Pusat Latihan Kota (PUSLATKOT) Kediri yang berjumlah 7 atlet laki-laki dan 8 atlet perempuan. Kemudian penelitian ini menggunakan teknik sampling jenuh dimana semua populasi digunakan sebagai sampel. Menurut Sugiyono (2011) bahwa,"sampling jenuh adalah teknik penentuan sampel bila semua anggota populasi digunakan sebagai sampel. Hal ini sering dilakukan bila jumlah populasi relatif kecil, kurang dari 30 orang". 
Untuk memperoleh data yang sesuai maka dalam penelitian ini menggunakan metode survey dan teknik tes. Metode ini dimaksudkan untuk mengumpulkan data-data mengenai kondisi fisik dengan menggunakan teknik tes. Macam-macam tes kondisi fisik antara lain :

a. Kekuatan otot tungkai dengan leg dynamometer.

b. Daya tahan otot perut menggunakan sit up selama 60 detik.

c. Kelincahan menggunakan shuttle run.

d. Daya ledak otot lengan menggunakan two hand medicine ball put .

e. Daya tahan kardiovaskuler dengan Multistage Fitness Test (MFT)

Data yang diperoleh tiap- tiap item tes merupakan data kasar dari hasil tiap tes yang dicapai. Hasil kasar tersebut diubah menjadi nilai t-skor dengan rumus t-skor sebagai berikut .

$$
\begin{aligned}
& \mathrm{T}=10\left(\frac{M-X}{S D}\right)+50 \quad \text { (data inversi) } \\
& \mathrm{T}=10\left(\frac{X-M}{S D}\right)+50 \quad \text { (data regular) } \\
& \text { Keterangan : } \\
& \mathrm{T} \quad=\text { nilai t skor } \\
& \mathrm{M} \quad=\text { nilai rata- rata kasar } \\
& \mathrm{X} \quad=\text { nilai data kasar } \\
& \mathrm{SD} \quad=\text { standar deviasi data kasar }
\end{aligned}
$$

Data yang sudah dirubah ke dalam t-skor, kemudian data dimaknai, yaitu dengan mengkategorikan data. Pengkategorian dikelompokkan menjadi 5 kategori yaitu: baik sekali, baik, cukup, kurang, kurang sekali. Pengkategorian menggunakan acuan 5 batas normal (Sudijono, 2008), adalah sebagai berikut:

Tabel 1. Skor Baku Kategori.

\begin{tabular}{ccc}
\hline No & Rentang Norma & Kategori \\
\hline 1 & $\mathrm{X} \geq \mathrm{M}+1,5 \mathrm{SD}$ & Baik Sekali \\
\hline 2 & $\mathrm{M}+0,5 \mathrm{SD} \leq \mathrm{X}<\mathrm{M}+1,5$ & Baik \\
\hline 3 & $\mathrm{M}-0,5 \mathrm{SD} \leq \mathrm{X}<\mathrm{M}+0,5 \mathrm{SD}$ & Cukup \\
\hline 4 & $\mathrm{M}-1,5 \mathrm{SD} \leq \mathrm{X}<\mathrm{M}-0,5 \mathrm{SD}$ & Kurang \\
\hline 5 & $\mathrm{X}<\mathrm{M}-1,5 \mathrm{SD}$ & Kurang Sekali \\
\hline
\end{tabular}

Langkah selanjutnya setelah data diperoleh adalah menganalisis data untuk menarik kesimpulan dari penelitian yang dilakukan. Analisis data yang digunakan dari penelitian ini menggunakan teknik analisis deskriptif kuantitatif dengan persentase. Menurut Sudijono (2008) rumus yang digunakan adalah sebagai berikut:

$$
\mathrm{P}=\frac{f}{N} \times 100 \%
$$

Keterangan :

$\mathrm{P}=$ persentase yang dicari

$f=$ frekuensi

$\mathrm{N}=$ jumlah responden

\section{HASIL}

Penelitian ini merupakan penelitian deskriptif, sehingga keadaan objek akan digambarkan sesuai dengan data yang diperoleh. Penelitian tentang analisis kondisi fisik atlet Wushu Sanda Puslatkot Kediri tahun 2018 dimaksudkan untuk mengevaluasi keadan kondisi fisik atlet secara keseluruhan. Dari hasil penelitian, perlu dideskripsikan pula secara masing-masing berdasarkan item tes yang dilakukan.

Data yang diperoleh dari 5 (lima) item tes didapatkan satuan skor yang berbeda-beda. Untuk mengatasi hal ini, data dirubah kedalam bentuk Tscore, sehingga diperoleh data dengan satuan yang sama. Data T-score lalu diambil rata-ratanya, dan selanjutnya data dikategorikan menjadi lima kategori sesuai dengan rumusmenurut Sudijono (2008). Pada masing-masing item tes juga dilakukan penghitungan, sehingga akan tampak kondisi fisik atlet dari masing-masing item tes. Berikut deskripsi data hasil penelitian.

a. Profil Kondisi Fisik Atlet Wushu Puslatkot Kota Kediri Tahun 2018

Data yang dianalisis telah dirubah ke dalam bentuk t-skor, sehingga satuannya sama. Hasil penelitian memperoleh nilai maksimum sebesar 325,8 dan nilai minimum 200,7. Mean diperoleh sebesar 250 dan standar deviasi sebesar 30,6. 
Journal of Sport and Exercise Science, Vol 2, No 1, 2019 (1-8)

Analisis Kondisi Fisik Atlet Wushu Puslatkot Kediri Dalam Menghadapi

Kejuaraan Provinsi Jawa Timur 2018

Berdasarkan rumus kategori yang telah ditentukan, analisis data memperoleh profil kondisi fisik atlet Wushu Puslatkot Kota Kediri tahun 2018 sebagai berikut:

Tabel 2. Distribusi Frekuensi Profil Kondisi Fisik Atlet Wushu Puslatkot Kota Kediri Tahun 2018.

\begin{tabular}{cccc}
\hline $\begin{array}{c}\text { Kelas } \\
\text { Interval }\end{array}$ & Frekuensi & Kategori & $\begin{array}{c}\text { Frekuensi } \\
\text { Relatif }\end{array}$ \\
\hline$>295,9$ & 1 & $\begin{array}{c}\text { Baik } \\
\text { Sekali }\end{array}$ & $6,67 \%$ \\
\hline $\begin{array}{c}265,3 \mathrm{~s} / \mathrm{d} \\
295,8\end{array}$ & 2 & Baik & $13,33 \%$ \\
\hline $\begin{array}{c}234,7 \mathrm{~s} / \mathrm{d} \\
265,2\end{array}$ & 7 & Cukup & $46,66 \%$ \\
\hline $\begin{array}{c}204,1 \mathrm{~s} / \mathrm{d} \\
234,6\end{array}$ & 4 & Kurang & $26,67 \%$ \\
\hline$>204$ & 1 & $\begin{array}{c}\text { Kurang } \\
\text { Sekali }\end{array}$ & $6,67 \%$ \\
\hline Jumlah & 15 & & $100 \%$ \\
\hline
\end{tabular}

Berdasarkan tabel 2, diperoleh data atlet dengan kategori baik sekali sebanyak 0 (0\%), kategori baik sebanyak 5 atlet (33,33\%), kategori cukup sebanyak 6 atlet (40\%), kategori kurang sebanyak 2 atlet $(13,33 \%)$ dan kategori kurang sekali sebanyak 2 atlet $(13,33 \%)$. Frekuensi terbanyak terdapat pada kategori cukup dengan frekuensi sebanyak 6 atlet. Lebih jelas dapat dilihat pada diagram berikut:

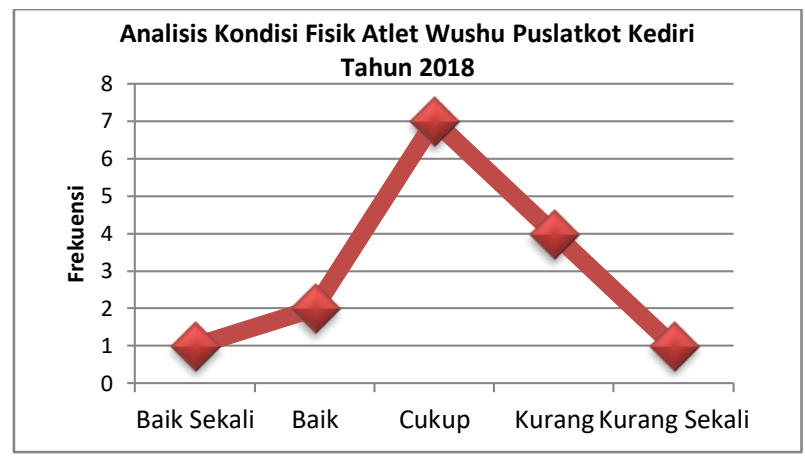

Grafik 1. Kondisi Fisik Atlet Wushu Puslatkot Kediri secara Keseluruhan.

b. Profil Kondisi Fisik Atlet Wushu Puslatkot Kota Kediri Tahun 2018 Berdasarkan MasingMasing Item Tes
1. Profil Kondisi Fisik Atlet Wushu Puslatkot Kota Kediri Tahun 2018 Berdasarkan Faktor Kekuatan Otot Tungkai.

Tabel 3. Distribusi Frekuensi Berdasarkan Faktor Kekuatan Otot Tungkai.

\begin{tabular}{cccc}
\hline $\begin{array}{c}\text { Kelas } \\
\text { Interval }\end{array}$ & Frekuensi & Kategori & $\begin{array}{c}\text { Frekuensi } \\
\text { Relatif }\end{array}$ \\
\hline$>65$ & 1 & $\begin{array}{c}\text { Baik } \\
\text { Sekali }\end{array}$ & $6,66 \%$ \\
\hline 55 s/d 64 & 4 & Baik & $26,67 \%$ \\
\hline 45 s/d 54 & 4 & Cukup & $26,67 \%$ \\
\hline 35 s/d 44 & 6 & Kurang & $40 \%$ \\
\hline$<34$ & & $\begin{array}{c}\text { Kurang } \\
\text { Sekali }\end{array}$ & $0 \%$ \\
\hline Jumlah & 15 & & $100 \%$ \\
\hline
\end{tabular}

Berdasarkan tabel 3, diperoleh data kekuatan otot tungkai atlet dengan kategori baik sekali sebanyak 1 atlet (6.66\%), kategori baik sebanyak 4 atlet $(26,67 \%)$, kategori cukup sebanyak 4 atlet $(26,67 \%)$, kategori kurang sebanyak 6 atlet (40\%) dan kategori kurang sekali sebanyak 0 atlet (0\%). Frekuensi terbanyak terdapat pada kategori kurang dengan frekuensi sebanyak 6 atlet. Lebih jelas dapat dilihat pada diagram berikut:

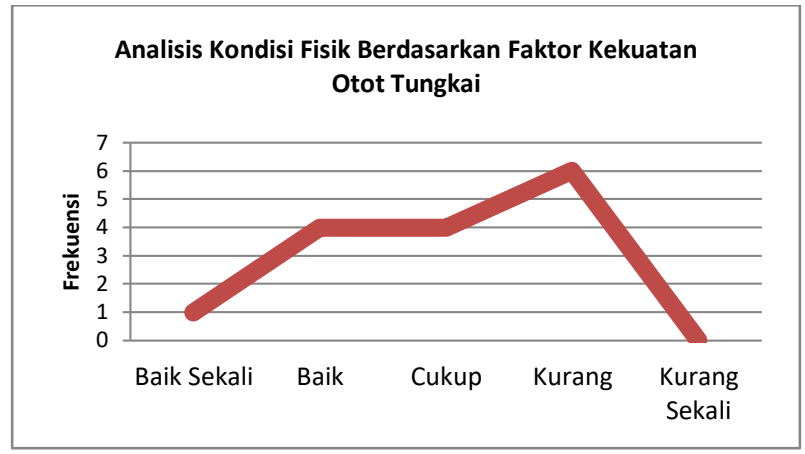

Grafik 2. Analisis Kondisi Fisik Berdasarkan Faktor Kekuatan Otot Tungkai.

2. Profil Kondisi Fisik Atlet Wushu Puslatkot Kota Kediri Tahun 2018 Berdasarkan Faktor Daya Tahan Otot Perut 
Journal of Sport and Exercise Science, Vol 2, No 1, 2019 (1-8)

Yulingga Nanda Hanief

Tabel 4. Distribusi Frekuensi Berdasarkan Faktor Daya Tahan Otot Perut.

\begin{tabular}{cccc}
\hline $\begin{array}{c}\text { Kelas } \\
\text { Interval }\end{array}$ & Frekuensi & Kategori & $\begin{array}{c}\text { Frekuensi } \\
\text { Relatif }\end{array}$ \\
\hline$>65$ & 2 & $\begin{array}{c}\text { Baik } \\
\text { Sekali }\end{array}$ & $13,33 \%$ \\
\hline 55 s/d 64 & 2 & Baik & $13,33 \%$ \\
\hline 45 s/d 54 & 5 & Cukup & $33,33 \%$ \\
\hline 35 s/d 44 & 5 & Kurang & $33,33 \%$ \\
\hline$<34$ & 1 & $\begin{array}{c}\text { Kurang } \\
\text { Sekali }\end{array}$ & $6,67 \%$ \\
\hline Jumlah & 15 & & $100 \%$ \\
\hline
\end{tabular}

Berdasarkan tabel 4, diperoleh data atlet dengan kategori baik sekali sebanyak 2 atlet (13,33\%), kategori baik sebanyak 2 atlet (13,33\%), kategori cukup sebanyak 5 atlet (33,33\%), kategori kurang sebanyak 5 atlet $(33,33 \%)$ dan kategori kurang sekali sebanyak 1 atlet $(6,67 \%)$. Frekuensi terbanyak terdapat pada kategori cukup dan kurang dengan frekuensi sebanyak 5 atlet. Lebih jelas dapat dilihat pada diagram berikut:

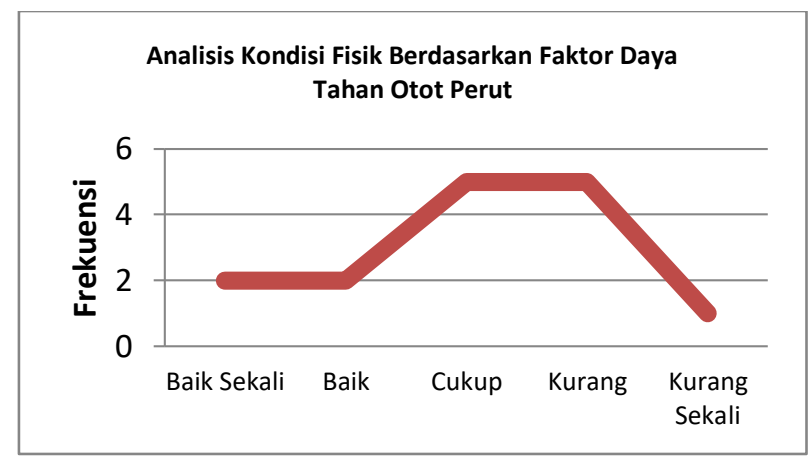

Grafik 3. Analisis Kondisi Fisik Berdasarkan Faktor Daya Tahan Otot Perut.

3. Profil Kondisi Fisik Atlet Wushu Puslatkot Kota Kediri Tahun 2018 Berdasarkan Faktor Berdasarkan Faktor Kelincahan

Tabel 5. Distribusi Frekuensi Berdasarkan Faktor Kelincahan.

\begin{tabular}{cccc}
\hline $\begin{array}{c}\text { Kelas } \\
\text { Interval }\end{array}$ & Frekuensi & Kategori & $\begin{array}{c}\text { Frekuensi } \\
\text { Relatif }\end{array}$ \\
\hline$>65$ & 0 & $\begin{array}{c}\text { Baik } \\
\text { Sekali }\end{array}$ & $0 \%$ \\
\hline 55 s/d 64 & 4 & Baik & $26,67 \%$ \\
\hline
\end{tabular}

\begin{tabular}{cccc}
\hline $45 \mathrm{~s} / \mathrm{d} 54$ & 8 & Cukup & $53,33 \%$ \\
\hline $35 \mathrm{~s} / \mathrm{d} 44$ & 1 & Kurang & $6,67 \%$ \\
\hline$<34$ & 2 & $\begin{array}{c}\text { Kurang } \\
\text { Sekali }\end{array}$ & $13,33 \%$ \\
\hline Jumlah & 15 & & $100 \%$ \\
\hline
\end{tabular}

Berdasarkan tabel 5, diperoleh data kelincahan atlet dengan kategori baik sekali sebanyak 0 atlet $(0 \%)$, kategori baik sebanyak 4 atlet $(26,67 \%)$, kategori cukup sebanyak 8 atlet (53,33\%), kategori kurang sebanyak 1 atlet $(6,67 \%)$ dan kategori kurang sekali sebanyak 2 atlet (13,33\%). Frekuensi terbanyak terdapat pada kategori cukup dengan frekuensi sebanyak 8 atlet. Lebih jelas dapat dilihat pada diagram berikut:

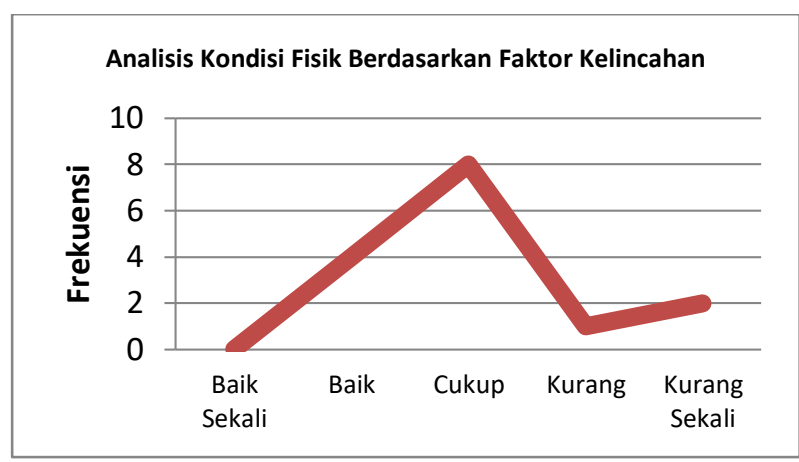

Grafik 4. Analisis Kondisi Fisik Berdasarkan Faktor Kelincahan.

4. Profil Kondisi Fisik Atlet Wushu Puslatkot Kota Kediri Tahun 2018 Berdasarkan Faktor Berdasarkan Faktor Power Otot Lengan

Tabel 6. Distribusi Frekuensi Berdasarkan Faktor Power otot Lengan

\begin{tabular}{cccc}
\hline $\begin{array}{c}\text { Kelas } \\
\text { Interval }\end{array}$ & Frekuensi & Kategori & $\begin{array}{c}\text { Frekuensi } \\
\text { Relatif }\end{array}$ \\
\hline$>50,63$ & 2 & $\begin{array}{c}\text { Baik } \\
\text { Sekali }\end{array}$ & $13,33 \%$ \\
\hline $\begin{array}{c}50,21 \mathrm{~s} / \mathrm{d} \\
50,62\end{array}$ & 3 & Baik & $20 \%$ \\
\hline $\begin{array}{c}49,79 \mathrm{~s} / \mathrm{d} \\
50,20\end{array}$ & 5 & Cukup & $33,33 \%$ \\
\hline $\begin{array}{c}49,37 \mathrm{~s} / \mathrm{d} \\
49,78\end{array}$ & 4 & Kurang & $26,67 \%$ \\
\hline$<49,36$ & 1 & $\begin{array}{c}\text { Kurang } \\
\text { Sekali }\end{array}$ & $6,67 \%$ \\
\hline Jumlah & 15 & & $100 \%$ \\
\hline
\end{tabular}


Berdasarkan tabel 6, diperoleh data Power Otot lengan atlet dengan kategori baik sekali sebanyak 2 atlet (13,33\%), kategori baik sebanyak 3 atlet (20\%), kategori cukup sebanyak 5 atlet $(33,33 \%)$, kategori kurang sebanyak 4 atlet $(26,67 \%)$ dan kategori kurang sekali sebanyak 1 atlet $(6,67 \%)$. Frekuensi terbanyak terdapat pada kategori cukup dengan frekuensi sebanyak 5 atlet. Lebih jelas dapat dilihat pada diagram berikut:

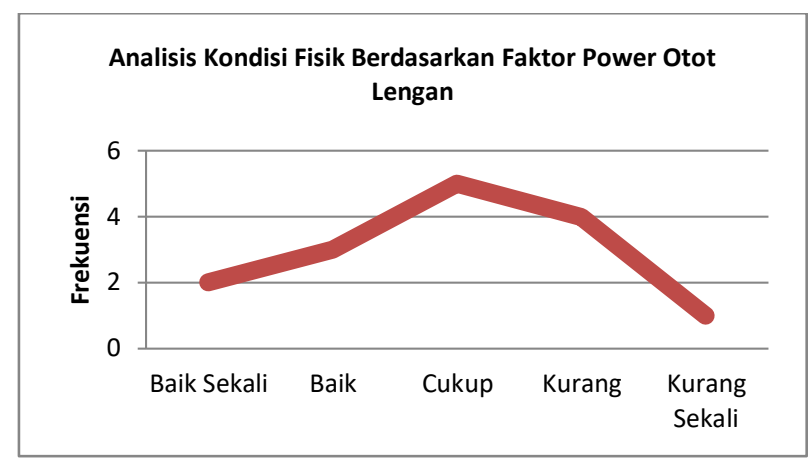

Grafik 5. Analisis Kondisi Fisik Berdasarkan Faktor Power Otot Lengan.

5. Profil Kondisi Fisik Atlet Wushu Puslatkot Kota Kediri Tahun 2018 Berdasarkan Faktor Berdasarkan Faktor Daya Tahan Jantung Paru (VO2max)

Tabel 7. Distribusi Frekuensi Berdasarkan Faktor Daya Tahan Jantung Paru (VO2max).

\begin{tabular}{cccc}
\hline $\begin{array}{c}\text { Kelas } \\
\text { Interval }\end{array}$ & Frekuensi & Kategori & $\begin{array}{c}\text { Frekuensi } \\
\text { Relatif }\end{array}$ \\
\hline$>65$ & 1 & $\begin{array}{c}\text { Baik } \\
\text { Sekali }\end{array}$ & $6,67 \%$ \\
\hline 55 s/d 64 & 4 & Baik & $26,67 \%$ \\
\hline 45 s/d 54 & 4 & Cukup & $26,67 \%$ \\
\hline 35 s/d 44 & 6 & Kurang & $40 \%$ \\
\hline$<34$ & 0 & $\begin{array}{c}\text { Kurang } \\
\text { Sekali }\end{array}$ & $0 \%$ \\
\hline Jumlah & 15 & & $100 \%$ \\
\hline
\end{tabular}

Berdasarkan tabel 7, diperoleh data daya tahan jantung paru atlet dengan kategori baik sekali sebanyak 1 atlet $(6,67 \%)$, kategori baik sebanyak 4 atlet $(26,67 \%)$, kategori cukup sebanyak 4 atlet $(26,67 \%)$, kategori kurang sebanyak 6 atlet (40\%) dan kategori kurang sekali sebanyak 0 atlet (0\%). Frekuensi terbanyak terdapat pada kategori kurang dengan frekuensi sebanyak 6 atlet. Lebih jelas dapat dilihat pada diagram berikut:

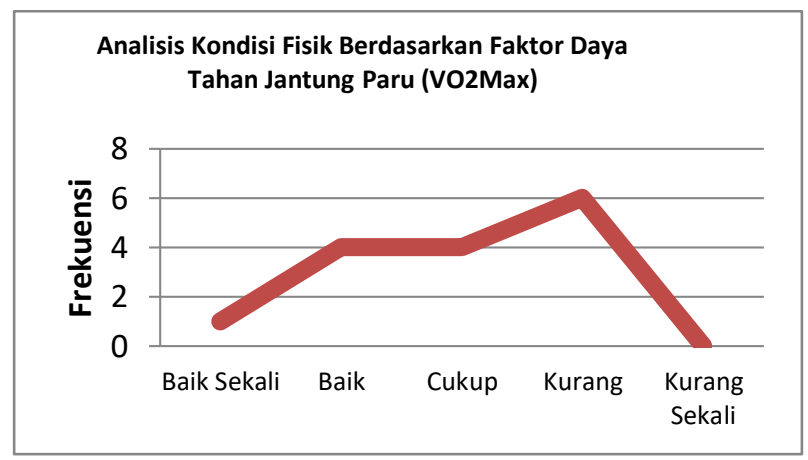

Grafik 6. Analisis Kondisi Fisik Berdasarkan Faktor Daya Tahan Jantung Paru (VO2Max).

\section{PEMBAHASAN}

Penelitian ini bertujuan untuk menganalisis persiapan atlet wushu Puslatkot Kediri tahun 2018 pada aspek kondisi fisik dalam menghadapi Kejuaraan Provinsi yang diselenggarakan di Ngawi tahun 2018. Untuk mengetahui kondisi fisik, para atlet melakukan beberapa rangkaian tes diantaranya adalah tes kekuatan otot tungkai, tes daya tahan otot perut, tes kelincahan, tes power otot lengan dan tes daya tahan jantung paru. Dari kelima item tes memiliki skor yang berbeda. Agar dapat diinterpretasikan, maka 5 data tersebut di ubah ke t-skor. Hasil kondisi fisik secara keseluruhan (tabel 2) menunjukkan kondisi fisik atlet wushu Kediri berada pada kategori cukup dengan frekuensi 7 atlet.

Wushu merupakan cabang olahraga beladiri yang menuntut kondisi fisik yang baik. Semua teknik dasar dalam wushu perlu ditunjang kondisi fisik yang baik. Kekuatan otot memegang peranan penting sebagai penunjang semua teknik dasar wushu, terutama kekuatan otot tungkai. Kekuatan otot tungkai merupakan faktor kondisi fisik yang digunakan dalam teknik menendang pada wushu. Latihan yang dapat diterapkan untuk mengembangkan kekuatan otot adalah latihan 
tahanan (resistance exercise). Faktor lainnya adalah daya tahan otot perut. Daya tahan otot perut diambil sebagai variabel dalam penelitian dikarenakan daya tahan otot perut memiliki kontribusi terhadap pertahanan (defence) dari serangan lawan. Perut menjadi area sasaran serangan lawan, selain itu daya tahan otot perut juga berperan dalam menyumbang kekuatan menendang atlet. Kelincahan berperan terhadap gerakan-gerakan yang tak diduga, terutama dalam pergerakan perpindahan tempat. Kelincahan diartikan sebagai kemampuan atlet dalam merubah posisi secara cepat (Widiastuti, 2015). Dengan kelincahan yang bagus, sesorang atlet akan memiliki banyak variasi dalam menyerang dan menghindar dari serangan lawan. Selain kelincahan, atlet wushu juga dituntut untuk memiliki power otot lengan yang baik. Power merupakan gabungan antara kekuatan dan kecepatan. Kegunaannya adalah untuk menyerang lawan dengan teknik pukulan. Usaha untuk menjatuhkan lawan tidak hanya dilakukan dengan tendangan saja, tetapi dengan pukulan yang memiliki power yang baik akan memiliki peluang dalam mengalahkan lawan. Yang paling penting lagi adalah daya tahan jantung dan paru. Pertandingan wushu dilakukan dalam 3 babak yang mana dalam 1 babak memiliki durasi 2 menit.

Kondisi fisik merupakan satu kesatuan utuh dari komponen yang tiudak dapat dipisahkan, baik dalam meningkatkan maupun pemeliharaannya (Hanief, Puspodari, Lusianti, \& Apriliyanto, 2017). Selama masa persiapan, perlu pembinaan atlet terkait kondisi fisiknya agar dapat mencapai tingkat fitness yang baik. Oleh sebab itu, penting sekali memiliki kondisi fisik yang baik dalam setiap latihan maupun pertandingan guna mencapai prestasi yang maksimal.

Kondisi fisik yang baik mustahil didapat tanpa program latihan yang terstruktur. Saat menerapkan program yang dirancang untuk meningkatkan kekuatan maksimal, harus dipertimbangkan dengan seksama beban eksternal apa yang harus digunakan untuk mencapai hasil yang diinginkan (Kirby, Erickson, \& McBride, 2010).

\section{SIMPULAN DAN REKOMENDASI}

Kondisi fisik atlet Wushu Puslatkot Kediri dalam menghadapi kejuaraan Provinsi Jawa Timur tahun 2018 dalam kategori sedang. Rekomendasinya adalah diharapkan para pelatih melibatkan aspek kondisi fisik pada penyusunan program latihannya dan melakukan evaluasi kondisi fisik secara berkala 3 bulan sekali agar tingkat kondisi fisik atlet terpantau.

\section{REFERENSI}

Ambara, A. P., \& Wijono, W. (2017). Hubungan Kondisi Fisik Terhadap Prestasi Atlet Wushu Sanda di Sasana KIM TIAUW Surabaya. Jurnal Prestasi Olahraga, 1(1-11).

Hanief, Y. N., Puspodari, P., Lusianti, S., \& Apriliyanto, A. (2017). Profil Kondisi Fisik Atlet Junior Taekwondo Puslatkot Kediri Tahun 2016 Dalam Menghadapi Pekan Olahraga Provinsi (Porprov) Jawa Timur Tahun 2017. Jurnal Kesehatan Jasmani Dan Olahraga (KEJAORA), 1(2), 17-28. Retrieved from http://ejournal.unibabwi.ac.id/index.php/kejaora/article/view/44 /31

Hanief, Y. N., Puspodari, P., \& Sugito, S. (2017). Profile of physical condition of Taekwondo Junior Athletes Pusklatkot (Training centre) Kediri city year 2016 to compete in 2017 east java regional Competition. International Journal of Physiology, Nutrition and Physical Education, 2(2), 262-265. Retrieved from http://www.journalofsports.com/archives/2 017/vol2/issue2/PartE/2-2-19

Harsono, H. (2015). Periodesasi Program Pelatihan (Cetakan Pe). Bandung: PT Remaja Rosdakarya.

Kirby, T. J., Erickson, T., \& McBride, J. M. (2010). Model for Progression of Strength, Power, and Speed Training. Strength and Conditioning Journal, 32(5), 86-90. https://doi.org/10.1519/SSC.0b013e3181f3e e5d

Lin, X., \& Lecheva, B. (2013). An Analysis of 
Wushu's Theoretical Concept and its Reflection in Wushu's Practice. IOSR Journal of Sports and Physical Education, 1(1), 4245.

Lu, C. (2008). Modern wushu: When Chinese martial arts meet Western sports. Archives of Budo, 4, 37-39.

Ma, X., Sun, W., Lu, A., Ma, P., \& Jiang, C. (2017). The improvement of suspension training for trunk muscle power in Sanda athletes. Journal of Exercise Science \& Fitness, 15(2), 81-88. https://doi.org/10.1016/J.JESF.2017.09.002

Mylsidayu, A. (2017). Analisis Kondisi Fisik Atlet PORDA Kategori Beladiri di Kota Bekasi Tahun 2016. Motion: Jurnal Research Physical Education, 3(67-78).

Nisa', W. (2017). Perkembangan Prestasi Sasana Wushu Sanda Kota Kediri dalam Event Porprov Jatim. Universitas Nusantara PGRI Kediri.

Selviah, P. (2015). Profil Kondisi Fisik dan Raihan Prestasi Pada Atlet Wushu Indonesia Sea Games-XXVIII 2013 di Myanmar. Universitas Pendidikan Indonesia.

Sudijono, A. (2008). Pengantar Statistik Pendidikan. Jakarta: Grafindo Persada.

Sugiyono. (2011). Metode Penelitian Kuantitatif dan Kualitatif dan $R \& D$. Bandung: Alfabeta.

Widiastuti. (2015). Tes dan Pengukuran Olahraga. Jakarta: PT Raja Grafindo Persada.

Wiwoho, H. agung, Junaidi, S., \& Sugiarto, S. (2014). Profil Kondisi Fisik Siswa Ekstrakurikuler Bola Basket Putra SMA N 02 Ungaran Tahun 2012. Journal of Sport Sciences and Fitness, 3(1), 44-48. 